\title{
Jean-Christophe Cavallin, Chateaubriand cryptique ou Les Confessions mal faites
}

\section{Laurence Richer}

\section{(2) OpenEdition}

1 Journals

\section{Édition électronique}

URL : http://journals.openedition.org/studifrancesi/36332

DOI : $10.4000 /$ studifrancesi.36332

ISSN : 2421-5856

Éditeur

Rosenberg \& Sellier

\section{Édition imprimée}

Date de publication : 1 juillet 2005

Pagination : 178

ISSN : 0039-2944

\section{Référence électronique}

Laurence Richer, "Jean-Christophe Cavallin, Chateaubriand cryptique ou Les Confessions mal faites », Studi Francesi [En ligne], 145 (XLIX | I) | 2005, mis en ligne le 30 novembre 2015, consulté le 19 avril 2021. URL : http://journals.openedition.org/studifrancesi/36332 ; DOI : https://doi.org/10.4000/ studifrancesi.36332

Ce document a été généré automatiquement le 19 avril 2021.

\section{(c)}

Studi Francesi è distribuita con Licenza Creative Commons Attribuzione - Non commerciale - Non opere derivate 4.0 Internazionale. 


\title{
Jean-Christophe Cavallin, Chateaubriand cryptique ou Les Confessions mal faites
}

\author{
Laurence Richer
}

\section{RÉFÉRENCE}

JEAN-CHRISTOPHe CAVAlLIN, Chateaubriand cryptique ou Les Confessions mal faites, Paris, Honoré Champion, 2003, pp. 216.

1 Le génie de Chateaubriand se définit à partir de la «double entrave à laquelle le dessin d'écrire une oeuvre autobiographique sans allusion au moi intime enchaîne le mémorialiste» (p. 10). Jean-Christophe Cavallin entreprend de prouver cette thèse à partir de la génétique textuelle, en montrant que, de version en version (à partir des Mémoires de ma vie), Chateaubriand se cache derrière son style et passe volontairement à une tonalité plus épique qu'intimiste. La réticence à se livrer s'écrit «sous le signe de la culpabilité» (p. 20), écrit l'auteur, en s'appuyant entre autres sur le fait que l'écriture des Mémoires d'outre-tombe manque de s'arrêter dans les années 1820 après les livres qui décrivent «le moi virginal» de l'enfance (p. 25).

On voit avec intérêt la double référence à Herder et Quinet («faire de la loi de l'humanité la loi de son être», p. 31), mais on peut regretter que la thèse centrale ne laisse pas place au problème de jonction entre l'influence herdérienne et la liberté possible: c'est pourtant essentiel pour Quinet comme pour Chateaubriand. Cavallin n'en arrive pas moins à une intéressante formule quand il écrit que Ballanche et Quinet montrent «à Chateaubriand la possibilité paradoxale de construire un personnage doué d'une vie intérieure extrêmement riche mais pure de toute vie intime» (p. 35).

3 L'épopée autobiographique, fusion réussie dans les Mémoires, suppose, dit Cavallin, que son héros ne soit pas l'idéalisation de vérités individuelles, mais la «personnification de grandes vérités historiques» (p. 47). Le moi serait alors allégorique. Il porte les morts, 
dans une relation réversible entre l'objet et le sujet du deuil (p. 70). Lucile, sans tombeau, a pour tombeau unique le cœur de son frère, qui devient une crypte (p. 74).

4 La dernière partie est centrée sur Venise. On a plaisir à voir mettre en lumière la quatrième partie des Mémoires, qui reste, malgré de beaux travaux, trop mal connue. Le dernier Chateaubriand, celui de la Vie de Rancé, date peut-être de cette ville, où il découvre la vieillesse (p. 111). L'invocation à Venise sur la plage du Lido fait partie d'une série d'apostrophes lyriques, successivement adressées à des hypostases féminines: Cavallin veut voir, dans cette volonté de s'adresser à des femmes au tombeau, un élément essentiel de poétique. L'écrivain attire à la vie ces figures, dans 1 '«opposition de l'exposition qui déchire et de l'inhumation qui protège» (p. 140).

5 L'écriture de ce livre est riche et précieuse. On a parfois l'impression que, face au postulat d'un ensemble crypté, le décryptage se fait trop systématique, mais, à la rigueur de l'intertextualité, qui donne quelques belles analyses, se substitue parfois un jeu de rapprochements impressionnistes, également bien venu. 